the structure of the proteins involved was previously completely unknown. Elucidation of the crystal structure thus requires the best X-ray phases. Earlier studies ${ }^{\mathrm{x} .11-1+}$ examined either known structures, or new structures known to be closely related by sequence and functional homology to known structures (see table). Even though the known structures may not have been used directly in the MAD structure determination, subjective bias in the interpretation of the electron-density map of initially modest quality is impossible to exclude. As crystallographers know only too well, it is much easier to locate a known structural motif, for example a cytochrome fold, a calcium-binding EFhand or a $\beta$-barrel, in such a map, than to identify a completely unknown motif.

Few proteins of interest to structural biologists are so obliging as to have a convenient, intrinsic heavy atom that exhibits anomalous scattering, so how is the technique to be generalized? First, crystallographers can now attempt to crystallize only a single heavy atom derivative in which a suitable extrinsic anomalous scattering atom has been chemically introduced, and ignore (at least initially) the native protein; the extent of isomorphism between the two is irrelevant to a successful structure determination via the MAD technique. More ingeniously, Hendrickson ${ }^{15.16}$ has proposed that selenomethionine may be biosynthetically incorporated into proteins in place of methionine. A methionine auxotroph of Escherichia coli grows quite happily on selenomethionine ${ }^{17}$, and can be used as the host for a recombinant plasmid designed to express the desired protein, in a selenomethionine medium ${ }^{15.16}$. Because on average one amino-acid residue in 58 is methionine, the phasing power of such selenium derivatives is high ${ }^{2.16}$. The approach is fairly general, and works also with Pseudomonas aeruginosa ${ }^{18}$. Extension to oligonucleotide structure determination via incorporation of bromouridine is clear.

A factor significantly limiting applications of the MAD technique is synchrotron beam time. Such studies require at least one week of actual data collection at the synchrotron ${ }^{2}$. It is hard to conduct MAD experiments with the extreme care demanded for success when the beam-

Guss, J.M. et al. Science 241, 806-811 (1988)

2. Hendrickson. W.A et al. Proc, natn. Acad. Sci. U.S.A (in the press)

3. Lye. R.C. et al. Proc natn. Acad. Sci. U.S.A. 77, 5884-5888 (1980).

Hendrickson. W. A etal. Meth. Enzym. 115,41-55 (1985) Okaya, Y. \& Pepinsky, R. Phws. Rev. 103, 1645 (1956)

6. Phizackerley R.P. Cork C.W.\& Merritt. E. A Nucl. instr. Meth. A246, 579-595(1986).

instr. Meth. A246, 579-595 (1986).
Karle. J. In. J. quant. Chem. 7, 357-367 (1980).

Hendrickson. W.A. et al. Proteins 4. 77-88 (1988)

. Templeton. D.H. \& Templeton. L.K. Acta Cryst. A41, 133-142(1985).

10. Hendrickson. W. A. \& Teeter M.M. Nature 290, 107-113 (1981)

11. Kahn, R. et al. FEBS Lett. 179, 133-137 ([985)

12. Harada. S. et al. J. appl. ('ryst. 19, $448-452$ (1986).

\title{
Bulgarian geneticist recognized at last
}

IT was not until June of this year, 40 years after his death, that Professor Doncho Kostov received the Dimitrov award - the highest national honour in Bulgaria - for his contribution to both international and Bulgarian science. The award marks the end of the period of intellectual vacuum suffered in Bulgaria since Stalin's time, and the eventual acknowledgement of the contribution of this eminent geneticist by his own nation.

Kostov died of a heart attack on 9 August 1949 at the age of 53 . His death was probably related to the forced introduction of lysenkoism to Bulgaria the year before. Kostov believed passionately in scientific truth. There had been attempts to introduce lysenkoism in Bulgaria as early as 1947, and as the pillar of genetic research in the country, Kostov was an openly declared opponent of the principles of lysenkoism imposed from Moscow. Kostov's assistant professor, Dimitar Shishkov, was assassinated on 24 May 1947, a national holiday, and his murderers were never found.

Kostov graduated from the Institute of Agriculture in Halle, Germany and obtained his doctorate in Germany. He worked at Harvard University with Edward Murray East before a spell in Leningrad and Moscow between 1932 and 1939. In the Soviet Union he collaborated with Nikolai Ivanovich Vavilov, Nobel laureate Hermann Muller, Georgii Karpechenko, Peter Lisitzin and others, all of whom were opponents of Lysenko.

During this time, Kostov and his collaborators published many significant papers both in the Soviet Union and in the West. Until 1939, he was a regular contributor to Nature. He was the first to describe the

line allocation committee is breathing down your neck, the X-ray beam or the detector electronics are briskly drifting, parts of the complicated apparatus keep breaking, your crystals are not cooperating, and your funding agency is complaining that your local and foreign travel budgets are enormous and always overspent. Plaintive comments along these lines that have escaped the principal authors' diplomatic axe can be found in many of the papers I have cited here $e^{1.2 .11-14}$. The next generation of dedi-

Korszun. Z.R. J. molec. Biol. 196. 413-419 (1987).

Krishna Murthy. H.M. et al. J. biol. Chem. (in the press).

Hendrickson. W.A. Trams. Am. (rist. Ass. 21. 11-21 (1985).

6. Hendrickson. W.A. in Crystallography in Molecular Biology (eds Moras. D. et al.) 81-87 (Plenum. New York. 1987).

17. Cowic. D.B. \& Cohen. G.N. Biochim. biophss. Actu 26. 252-261 (1957)

18. Frank. P. et al. J. biol. (hem. 260, 5518-5525 (1985).

19. Amemiya. Y. et al. Nucl. instr. Meth. A266, 645-653 (1988)

Whiting, B.R., Owen, J.F. \& Rubin. B.H. Nucl. instr Meth. A266, 628-635 (1988).

Arndt. U.W. e't al. Nuture 298, 835-838 (1982)

2. Moffat. K., Szebenyi. D. \& Bilderback. D. Science 223. $1+23-1+25\left(19 x^{4} 4\right)$ andrigene haploidics in 1929; he studied the mutagenic action of alkaloids in 1930; and he photographed the discoid structure of the chromosomes of the fruitfly Drosophila melanogaster, also in 1930. Kostov's monograph on haploidics, published in Holland in 1941, was a pioneering paper.

Kostov's major work "Cytogenetics of the genus Nicotiana" was published in 1943, simultaneously in Bulgarian and in English. This paper provided important proof of the role of the chromosome in evolution. It was this paper more than any which stalinist scientists used to harass Kostov to his death.

The Soviet geneticists with whom Kostov published some of his work, for example N.S. Arutvunova, A. Orlov and N. Sarana, were killed during the Lysenko period because of the liberty that they had taken in publishing in the West. But as it turned out, only two geneticists in Bulgaria actually died as a result of stalinist victimization - Shishkov and Kostov. But about 100 other followers of the chromosome theory of evolution were tormented, dismissed or demoted. Their work could not be published for decades and they could not obtain academic qualifications.

Several historians attribute the lengthy obscurity of Bulgarian science to the period of Stalin's influence. But this can hardly be true for the whole of the past 40 years. In Bulgaria, as in other countries, the advent of lysenkoism was a moment when ignorance was raised to nationwide dimensions. Iskren Azmanov

Iskren Azmanov is in the Department of History at the Bulgarian Academy of Science, 1113 Sofia, Capaev Str. 52/17, Bulgaria.

cated synchrotron radiation sources, the ESRF at Grenoble and the APS at Argonne, may alleviate the capacity problem by 1995 - but with the push in protein engineering and structure-based drug design, can the field wait?

Perhaps storage phosphor/image plate detectors ${ }^{19.211}$ will replace the precise but complicated and slow MWPC detectors; rather than scanning a narrow bandpass monochromator to four discrete wavelengths, perhaps a wider bandpass multilayer monochromator in conjunction with unusual focusing ${ }^{21}$ or Laue oscillation ${ }^{2-}$ techniques will be more effective; and perhaps the reliability, stability and accessibility of existing dedicated synchrotron radiation sources will be improved by their enthusiastic staffs. The future of the MAD technique, and of structural biology in general. will continue to depend in substantial measure on technological questions as well as scientific ones.

Keith Moffat is in the Section of Biochemistry, Molecular and Cell Biology at Cornell Univer sity, Ithaca, New York 14853, USA. 